\title{
Objectification of Caddy in William Faulkner's The Sound and the Fury
}

\author{
Fang Xiang ${ }^{1, *}$ \\ ${ }^{1}$ School of Foreign Languages, Leshan Normal University, Leshan, Sichuan, China \\ *Corresponding author. Email: 44653664@qq.com
}

\begin{abstract}
The Sound and the Fury is not only about the downfall of the prominent Compson family, but also about the great effect brought by the loss of Caddy on the family. This paper tries to analyse Caddy's degeneration mainly from the perspectives of her three brothers, the three narrators in the novel, Benjy, Quentin and Jason who tried to keep Caddy static and deprived her of the freedom to pursue her happiness and value in her life through their objectification of her to be the objects such as the tree, the monument of honor or a commodity they wanted her to be respectively.
\end{abstract}

Keywords: Caddy, Objectification, Chastity, Degeneration.

\section{INTRODUCTION}

The Sound and the Fury tells a story of the decline of Compson family, a southern prominent family. The decline of the Compson family is revealed through the idiot son called Benjy, the suicide of the eldest son called Quentin and the vicious son called Jason. The three brothers struggled in the world which suffered a lot with the abolishment of the slavery after the civil war. The novel is narrated by the three brothers respectively in the first three chapters and by an omniscient narrator in the fourth chapter, but the center of their narration focused on their sister called Caddy. What made the reader confused is Caddy was absent in the novel though she was the center of the novel. Apparently, the novel talks about the three brothers' life and mentality, but in fact it is a story about the sister Caddy who had a great effect on the three brothers' life. To Benjy, she seemed like his mother; To Quentin, she was more of a monument of the southern morality; To Jason, she was just a bitch. Since Caddy was indispensable for the novel, why was Caddy absent in the novel, and why did the three brothers told her story rather than herself?

\section{LITERATURE REVIEW}

Some Critics thought the absence of Caddy in the novel reflected Faulkner's chauvinism who deprived the woman the right of speaking. On the contrary, Caddy was Faulkner's favourite girl and sister, as he put it "because Caddy was still to me too beautiful and too moving to reduce her to telling what was going on, that it would be more passionate to see her through somebody else's eyes" [1]. Baum made a deep analysis on the Caddy's characters and her changes through her daily interaction with her brothers and lovers and came to the conclusion "she represents the virtues like love, compassion, sacrifice in a family which is destroying itself through the lack of these qualities"[2]. John L. Longley commented that Caddy's tragic is attributed to the morbid atmosphere of the Calvinism in the rural South which regarded Caddy's sexual experience as the ultimate horror which further destroyed the whole family [3]. Sciolino in his essay explained Caddy was regarded an exchange object by Quentin, Jason and Mrs Compson [4]. According to the previous criticism on Caddy, there is a consensus that Caddy was a lovely, brave and compassionate girl who was at last destroyed by the family members and the decadent South. While the critics ignored the problem why Caddy's story was told by the three brothers rather than herself, therefore the thesis here tries to discuss the reason that leads to Caddy's final degeneration to be the prostitute of a Nazi officer from the perspective of three brothers who in fact intended to objectify Caddy to be some objects they wanted her to be and deprived her of freedom to pursue her love and value. 


\section{OBJECTIFICATION OF CADDY TO BE A STATIC OBJECT BY BENJY}

The first chapter is narrated by Benjy, but it is not a real narration made by Benjy, for he was an idiot who lacked the ability to narrate the story, it is just the overflow of Benjy's stream of consciousness. Benjy's mental handicap prevented him from narrating the story in a clear and logical way. The difficulty in the chapter is the arbitrary shift of the evens and the time in Benjy's mind. His consciousness shifted from one incident to another, which made the readers confused with the sequence of the events. At the beginning of the story, Benjy played around the pasture with Luster, when one person called Caddie which is pronounced the same as his sister, Benjy's mind suddenly shifted to the incident that Caddy send a letter to Mrs Patterson for Uncle Maury with him, and then shifted to another time he himself send a letter to Mrs Patternson for Maury. When his foot touched the water, his mind shifted to a time when he, Caddy, Quentin, Jason and Versh played in the river where Quentin had a quarrel with Caddy, and then shifted to the night when Damuddy died and the time when he sensed Caddy lost the fragrance of the tree which symbolized Caddy's lost of her virginity. Though his consciousness shifted many times, it only centered on the person Caddy who had ever really loved him and treated him softly and warmly in the family. The shift of the consciousness seemed disordered and fragmented, but this part also provided us a miniature of the characters of the children in the family and enabled us to understand their behaviors and fates in the future.

The world presented through Benjy's mind is intuitive impression for Benjy perceived the world through his sensory perception, and he lacked the ability to narrate and comment on the things. Chronology is beyond him, he cannot distinguish them from now. All time is the same to him, a sort of continuous present in which he does not know is memories are only memories [5]. Without time conception, Benjy's mind jumped capriciously backward and forward, connecting the present with the past. The shift of his mind is triggered by the objects he saw. In his stream of consciousness, some significant events are presented through the characters' dialogues, from which the readers can probe into their characteristics. In Benjy's consciousness, we see a curious, brave and vivacious girl who didn't perform to the rule of the patriarchal society. When she played with the boys in the river, she dared to put off the wet dress though Quentin tried to prevent it and even slapped her. When Quentin was worried that their playing in the river would be told to Damuddy by Jason, Candy said "I don't care whether they see or not. I am going to tell myself" [6]. Caddy was the only child brave enough to climb up the tree to see what happened in the room the day Damuddy died. Caddy always pretended to be a leader whenever the children were together. When Dummady died, Caddy pleaded his father to let her be the leader among the children. Caddy would fight with Jason when she found Jason cut up the paper dolls made for Benjy, "He cut up all Benjy's dolls, I'll slit his gizzle" [7]. Because of Benjy's inability to make any analysis on the past events, the things filtered through his mind gave the readers an objective picture of Caddy in her childhood. Though Benjy was unable to perceive the world rationally as his brother Quentin, he could feel the love of Caddy who treated him very well like a mother. It is to Caddy and only Caddy that he looks for emotional support [8]. Caddy's kindness and humanity was revealed in the daily life when she was with Benjy. When Benjy was cold, Caddy would hold his hands and make them warm. When he wanted to go out, Caddy would beg her mother to take him outside. When Benjy was crying, Caddy would hold him and bring the cushion to comfort him. Though Benjy was an idiot, he was very sensitive of any changes in Candy. When he saw Caddy dressed like an adult and smelled the perfume on Caddy, he cried and repulsed Caddy. In order to comfort Benjy, Caddy gave the perfume to Disley and said we didn't like it. When he found Caddy had a date with a man and cried, Caddy promised him she would never do it again and washed herself "Caddy knelt down in the dark and held me. I won't, I won't any more, ever. Benjy, Benjy. Then she was crying, and I cried, and we helld each other. We went into the kitchen and turned the light on and Caddy took the kitchen soap and washed her mouth at the sink, hard. Caddy smelled liked trees" [9]. Caddy was the only person in the family who would gave the tender love to Benjy, took care of him carefully, and even sacrificed herself for him. While Benjy's dependence on Caddy was selfish and exclusive, he would try to prevent the changes in Caddy. He just treated Caddy as a tree, which meant he just objectified Caddy. "Candy smelled like the tree", whenever he sensed the changes in Candy's body, he would say "Candy didn't smell like a tree". Benjy would threaten Caddy with his crying when he perceived the changes in Candy, by this way, he intended to prevent the change and growing of 
Candy and regarded Caddy as his own object which should remain static. After Candy got married and left the house, the comfort that Benjy could get is from the daily articles she had ever used, such as the her slipper, and the cushion. Candy's change from a girl to a maid was presented to the readers through Benjy's recollection. Caddy's usage of the perfume, and her date with Charles showed the girl's pursuit of freedom and love, and the ideal lady conception in the old south is collapsed with the invasion of the northern industrialization. But Candy gave up her own pursuit and freedom under the threaten of Benjy whom she cared about a lot, she dared to misbehave in the patriarchal society and not afraid of any punishment, but she felt guilty about hurting Benjy, so her absence in the novel showed she succumbed to the requirement of Benjy and struggled to be whom Benjy wanted her to be.

\section{OBJECTIFICATION OF CADDY TO BE THE MORAL MONUMENT BY QUENTIN}

In Quentin's part, Quentin's narration is more obscure than that of Benjy, for his narration was not only fragmented and chaotic, but also full of arcane thinking on life. Quentin was a college student who was sensitive in his perception of the world. In fact this part cannot be regarded as a normal narration, because it was made before Quentin's death, so it would be better treated as the flow of his stream of consciousness rather than a real narration. This part gives the readers an approach to see the changes of Candy in her adolescence. Southern society was almost from the outset a family-centered society. Father and master in one, the slaveholding planter of the prewar south was the source and locus of power: as paterfamilias, he claimed full authority over wife and children. After the civil war, when the socioeconomic foundations of autocratic father rule began at last to crumble, paternalism no doubt survived for many years among the remnants of the plantation system, and so did the patriarchal family structure till the early decades of the twentieth century [10]. With the collapse of the southern plantation system and the decline of the family, Quentin struggled to cope with the collapse of the southern traditional hierarchy and morality. In his narration, Caddy was also his centre, for his pains was mainly caused by Caddy's lost of chastity. Since South is a place worshiping the honor and dignity of a family, the chastity of the woman became dominant and cherished in that culture. Therefore, Caddy's loss of chastity was a humiliation to the whole family. What's more,
Quentin, as the only college student in the family valued honor of the family more than other family members, he was naturally the defender of the family's glory as a symbol of a patriarchal power. Because of his belief in the honor, Caddy was objectified by him to be the monument of the South ideal morality. He practiced the spirit of a southern cavalier which can be summoned as courtesy, honor, valor and generosity.[11] When they were young, Quentin, Candy, Versh played in the river, and Caddy planned to took off her wet dress, Quentin tried to stop her. "I bet you won't." "I bet I will." When Caddy took her dress off and didn't have anything but her bodice and drawers, he slapped Caddy. His behavior showed his intention of defending his sister's reputation though he was just a child. Before his suicide, when he wandered on the street, he met an Italian girl who was too poor to buy bread. Out of sympathy, He bought her a piece of bread and even helped her to find the way back home. His protection of the little girl showed he was the true defender of the south cavalier, and thus Caddy's virgin was very significant to Quentin. In his stream of consciousness, his grief about Caddy's lost of virgin is overflowing. In order to defend Caddy and the family's reputation, $\mathrm{He}$ even tried to challenge Dalton to fight by which he hoped he could prevent their contact. But he was not brave enough as Henry, the brother of Judith, who killed Bon for preventing their marriage to protect the reputation of the family in Absalom, Absalom. He behaved cowardly and dared not to receive the gun given by Dalton to shot at him. Moreover, he was hurt and faint when tried to fight against Dalton. When Caddy came and found Quentin lying down, Caddy was very nervous and promised him she would never meet Dalton just because she wanted to protect Quentin, the same as she gave up the perfume when Benjy was crying. Since then, Candy's eyes lost the brightness, and became gray. "she looked at me then everything emptied out of her eyes and they looked like the eyes in statues blank and unseeing and serene" [12]. Though Caddy yielded to Quentin's authority, she lost her lover, and also lost her hope and passion for the life, so she became depressed and silent like a stone. The fact that Caddy's lost of virgin meant the collapse of the traditional southern morality couldn't be stood by Quentin who regarded defending the glory of the family as his mission, so he fabricated a lie that he had an incest with Caddy. "Quentin attempts to alter the nature of her sin by merely asserting that he and she have committed incest" [13]. By this way, he shifted the evil from 
Caddy to himself, and defended the sister's reputation. In fact, Caddy was just objectified by Quentin as a monument of the southern lady who represented the past glorious South and its traditional ethics. Since Caddy was the monument of the Southern morality, Quentin also tried to prevent any changes in Caddy. Quentin's objectification of Caddy results from a loss and a disappointment. On the one hand, the loss of the glory of the noble family forced him to objectify Caddy to be a symbol of moral virtues which could last forever. On the other hand, he was disappointed by his father who should have taken the role as the authority to punish Caddy's degeneration and defend the glory and morality of the family. When he tried to seek comfort from his father after Caddy lost her virgin, his father told him "women are never virgins. Purity is a negative state and therefore contrary to nature". Here Mr. Compson seemed to interpret the sexual life to women as a natural part of their life, which shouldn't be rebuked. But his philosophy against the morality made Quentin disappointed and began to assume the role as a father to execute his arbitrary domination over Caddy, so he tried to stop Caddy's contact with Dalton. He even imagined himself to be Dalton's mother and prevent the conceiving of Dalton, "If I could have been his mother lying with open body lifted laughing, holding his father with my hand refraining, seeing, watching him die before he lived" [14]. Quentin was anxious about the loss of Caddy. He repeatedly asked Caddy, "do you love him, do you think him now?" He didn't regard Caddy as an independent girl, he tried to objectify her and possess her. He always interfered with Caddy's private things, because he was afraid of the loss of Caddy. He not only preventing Caddy's contact with Dalton, he also tried to stop Caddy from marrying Herbert who was a liar and a villain in his eyes. In order to protect Caddy's reputation, Quentin even hoped to perish with Candy "If it could just be a hell beyond that; the clean flame the two of us more than dead. Then you will have only me then only me then the two of us amid the pointing and the horror beyond the clean flame" [15]. Since time couldn't be retreated, and Caddy couldn't return to the virgin state, Quentin would rather destroy themselves in order to preserve her chastity. Caddy's absence showed her submitting to Quentin and gave up her pursuit for love.

\section{OBJECTIFICATION OF CADDY TO BE A COMMODITY BY JASON}

The third chapter was narrated by Jason, a malicious son in the family. Jason was a thorough villain whose life purpose was nothing but to accumulate money through all mean ways. Jason's way of pursuing the money represented the collapse of the Southern plantation economy with the invasion of the northern industry. After the death of Quentin and Mr. Compson, the departure of Caddy, Jason also assumed the role as a patriarch in the family. As a son in a degenerating family, he felt anguished at supporting the family with an idiot brother, a weak and neurotic mother, an illegitimate girl left by his sister Caddy and the black servants. He felt agonized at the money made by the sale of Benjy's pasture went to Caddy's wedding and Quentin's fees in Harvard University, both of which failed at last. He treated his niece little Quentin viciously, treated his mother Mrs Compson coldly and always talked to her sarcastically and always complained before Disley, a respectable servant in the family. He was always furious and cynical toward the world. All Jason's disappointment and fury resulted from the collapse of the family and Caddy's divorce with her husband Herbert who had ever promised him a decent job in the bank. At the beginning of this part, Jason said "Once a bitch always a bitch." To Jason, Candy was just a prostitute. If Caddy's lost of the chastity destroyed the glory of the family to Quentin, it destroyed a good chance to make money to Jason. Jason never really cared about his sister, but objectified her as a commodity which could be exchanged with Herbert for a good job. But Caddy's failure in her marriage deprived Jason the possibility to work in a bank. Jason attributed his failure to Caddy, and tried to revenge on Caddy. Jason attempts to balance his psychological accounts by blackmailing Caddy, using her daughter as a venture [16]. He secretly possessed the money given to Quentin by Caddy and the money sent to his mother. He took the advantage of Caddy's desire to see her daughter Quentin and extorted Caddy. He promised to give a chance for Caddy to see her daughter just for one second on the premise that Caddy must give him 100 dollars. As Caddy had said Jason's blood was cold, it is cruel for Jason to ride the horse very fast when Caddy just had one second glimpse of her daughter and was driven to be mad by Jason's cruelty. "She stood there looking at me, shaking like an ague fit, her hands clenched and kin of jerking" [17]. If Quentin destroyed Caddy's hope 
for happiness, Jason drove Caddy to be desperate and mad.

\section{CONCLUSION}

Caddy's helplessness was exhibited through the three brothers' narration and recollections, by which Faulkner showed how a brave girl lost her hope and passion for life and helplessly degenerated to a mistress of a Nazi officer in such a patriarchal society. Each of the three brothers tried to make Caddy the objects in their favor. Caddy was objectified to be a fragrant tree by the idiot brother Benjy who depended on her for emotional support; objectified to be the moral monument of the South by Quentin who wanted to preserve the glory of his family and the virtues of women in the South forever; and objectified to be a commodity by Jason who just treated her as a tool for making money. In order to comfort Benjy, to protect Quentin and her daughter, she submitted to the reality and the brothers' requirements, she received the objectification of herself and finally degenerated to be a prostitute of a Nazi officer. Therefore the story is not just about the loss of the glory of the family and South, it is about the loss of a beautiful Candy. What Faulkner wanted to retain is the virtues Caddy embodies, like love, vitality, braveness and independence, while the precious qualities were destroyed by the three brothers who represented the patriarchal rule in the South society and objectified Caddy to what they wanted her to be. Since Caddy received the objectification of herself from the three brothers, her absence in the novel showed she failed to take action to fight against their objectification and the vanishing of the virtues in the South Faulkner wanted to preserve. Making Caddy absent and silent in the novel is Faulkner's technique and private emotion, by which he tried to preserve the most lovely girl in the old South. Caddy loses these qualities is her tragedy, and the reminder of the novel depicts the tragic changes as the world finally destroys her courage and her love [18].

\section{AUTHORS' CONTRIBUTIONS}

This paper is independently completed by Xiang Fang.

\section{REFERENCES}

[1] Gwynn, Frederick L \& Blotner, Joseph L. Faulkner in the University [M]. Charlottesville, 1959.
[2] Baum, Catherine B. The Beautiful One: Caddy Compson as Heroine of The Sound and The Fury. [J] Modern Fiction Studies. Vol. 13, No. 1, WILLIAM FAULKNER SPECIAL NUMBER (Spring 1967), pp. 33-44.

[3] Longley, Jr., John L. Who Never Had a Sister: A Reading of The Sound and The Fury [J].An Interdisciplinary Critical Journal, Vol. 7, No. 1, (Fall, 1973), pp. 35-53.

[4] Sciolino, Martna. Woman as object of Exchange in Dickens' Great Expectations and Faulkner's The Sound and The Fury [J]. Mississippi Review,1989,Vol.17, No. 1/2, pp.97-128.

[5] Longley, Jr., John L. Who Never Had a Sister: A Reading of The Sound and The Fury [J].[8]An Interdisciplinary Critical Journal, Vol. 7, No. 1, (Fall, 1973), pp. 35-53.

[6] Faulkner, William. The Sound and the Fury. Beijing: Central Compilation \& Translation Press, 2013, p.14.

[7] Faulkner, William. The Sound and the Fury. Beijing: Central Compilation \& Translation Press, 2013, p.52.

[8] Longley, Jr., John L. Who Never Had a Sister: A Reading of The Sound and The Fury [J]. An Interdisciplinary Critical Journal, Vol. 7, No. 1, (Fall, 1973), pp. 35-53.

[9] Faulkner, William. The Sound and the Fury. Beijing: Central Compilation \& Translation Press, 2013, p.37.

[10] Bleikasten, Andre. Sutpen as Patriarch: Critical Essays on William Faulkner//The Sutpen Family [C]. ed., Arthur F. Kinney, New York: G.K Hall\&Co,1996.

[11] Xin Wang: Trauma, Memory, and History: A Study of the American Southern Trauma Novel [M]. Chengdu: Sichuan University Press, 2013.

[12] Faulkner, William. The Sound and the Fury. Beijing: Central Compilation \& Translation Press, 2013, p.130.

[13] Bowling, Lawrence. The Theme of Pride in The Sound and The Fury [J]. Modern Fiction Studies, 1965.Vol.11, No.2, pp.129-139.

[14] Faulkner, William. The Sound and the Fury. Beijing: Central Compilation \& Translation Press, 2013, p.65. 
[15] Faulkner, William. The Sound and the Fury. Beijing: Central Compilation \& Translation Press, 2013, p93.

[16] Sciolino, Martna. Woman as object of Exchange in Dickens' Great Expectations and Faulkner's The Sound and The Fury [J]. Mississippi Review, 1989,Vol.17, No. 1/2, pp.97-128.

[17] Faulkner, William. The Sound and the Fury. Beijing: Central Compilation \& Translation Press, 2013, p163.

[18] Baum, Catherine B. The Beautiful One: Caddy Compson as Heroine of The Sound and The Fury. [J] Modern Fiction Studies. Vol. 13, No. 1, WILLIAM FAULKNER SPECIAL NUMBER (Spring 1967), pp. 33-44. 